\title{
Genetic Diversity and Principal Component Analysis for Grain Quality and Productivity Traits in Sorghum [Sorghum bicolor (L.) Moench]
}

\author{
Ashwini Karadi $^{1 *}$ and S.T. Kajjidoni ${ }^{2}$ \\ ${ }^{1}$ Indian Institute of Horticultural Research, Banglore-560089, \\ (Karnataka), India \\ ${ }^{2}$ University of Agricultural Science, Dharwad- 580005(Karnataka), India \\ *Corresponding author
}

\begin{abstract}
A B S T R A C T
An investigation was carried out to assess nature and magnitude of genetic diversity for grain quality traits and productivity traits in mini core collection of sorghum. Mini core accessions were grouped into 15 clusters, where in cluster III had largest with 21

Keywords

Sorghum, Diversity,

Principal

component, Mini

core, Cluster

Article Info

Accepted:

15 August 2019

Available Online:

10 September 2019 accessions whereas cluster XIII had minimum with 5 accessions. Plant height contributed maximum divergence with $46.2 \%$. The inter cluster distance $\mathrm{D}^{2}$ value ranged widely with minimum values of $\left(D^{2}=197.61\right)$ and maximum value $\left(D^{2}=5541.42\right)$ indicating high diversity among mini core and it was desirable to select mini core from clusters showing high inter cluster distance. Diversity among cluster varied from $\left(D^{2}=255.25\right)$ to $\left(D^{2}=4906.5\right)$ inter cluster distance. Principal component analysis revealed that, three out of nine principal components with eigenvalues $>1$ were extracted. These three components contributed $58.29 \%$ of the total variation among the mini core. Principal components first three contributed, $22.73 \%, 17.99 \%$, and $15.50 \%$, respectively toward the variation observed among accessions. Variation relative to the first component was associated with seed yield per plant, 100 seed weight, seed volume, bulk density, seed size. The second principal component was associated with plant height, ear head length, ear head width, seed yield per plant, 100 seed weight, seed volume and seed size. The third principle component was associated with ear head width, 100 seed weight, seed yield per plant and seed size.
\end{abstract}

\section{Introduction}

Sorghum [Sorghum bicolour (L.) Moench] is one of the important cereal crop in the world, which is grown in Africa, Asia, USA, Australia and Latin America. It is the fourth most important cereal crop following rice, wheat, maize and staple food in the same central parts of the world. Worldwide, it is cultivated on 41.07 million ha area with production of 58.42 million tones in the year approx., 2019-20 (Anonymous 2019a). In India, sorghum having 5.00 million ha area with 4.5 million tones production and 900 $\mathrm{kg} / \mathrm{ha}$ productivity in the year 2019-20 (Anonymous 2019b). Sorghum shows extreme genetic diversity (Sanchez et al., 2002) and is predominantly self-pollinating, with varying 
levels of outcrossing. Sorghum grown in rabi season is characterized by its excellent grain quality, exclusively utilized for human consumption and hence fetches higher market price as compared to kharif.

Understanding of genetic diversity of a species is fundamental in any crop improvement programme. For such species, in general the parents with more genetic divergence are expected to yield heterotic hybrids in addition to generating a broad spectrum of variability in segregating generations. The $\mathrm{D}^{2}$ statistic is a useful multivariate statistical tool for effective discrimination among various genotypes on the basis of genetic divergence (Murty and Arunachalam, 1966; Sonawane and Patil, 1991). Diversity analysis provides information on deciding choice of parents from distantly related clusters to secure yield improvement in sorghum. A better understanding of genetic diversity in sorghum will facilitate crop improvement (Jayarama Chandran et al., 2011). Diversity in germplasm is important for any breeding program, since it directly affects the potential for genetic gain through selection (Kotal et al., 2010). Genetic diversity among the genotypes serves as a way to adapt to changing environments and their utilization in crop improvement programme. However, reports on genetic diversity among the rabi sorghum is very limited. Therefore there is a need to evaluate the available accessions for genetic diversity.

Principal component analysis is a multivariate technique for examining the relationships among several quantitative variables (Johnson 2012). It is the most common technique used in variability studies and numerical classification; it is useful in grouping varieties based on their similarities (Bello 2004). Principal component analysis is an important breeding tool commonly used by breeders to identify traits that could be used to discriminate crop genotypes (Das 2000; Yan and Kang 2003). Establishing suitable selection criteria for identifying genotypes with desirable traits is useful in developing improved varieties. Analysis of variability among traits and knowledge of associations among traits contributing to yield would be of great importance in planning a successful breeding program (Mary and Gopalan 2006). To date, in Niger, no study has been carried out with the objective to assess diversity in sorghum based on traits mentioned above by using multivariate analysis. Therefore, the objective of this study is to determine genetic diversity of sorghum inbred lines, which would be helpful in enhancing the efficiency of sorghum breeding program.

Suitable selection criteria for the identification of genotypes with desirable traits are essential for successful varietal improvement programs. Analysis of variability among traits and the identification of associations among various traits contributing to yield would facilitate successful development of high yielding varieties (Mary and Gopalan 2006). However, selecting only for grain yield may not be efficient for developing varieties for adoption by farmers; selection, which integrates yield and farmer-preferred traits, should provide more appropriate varieties (Alvi et al., 2003). The identification of yield-related traits could result in more effective selection for yield and farmer-preferred traits. The high level of genetic diversity and characterization of accessions integrated into world collections is essential in order to classify, mange exotic germplasm, collect and ultimately utilize the different genetic improvement of the crop.

\section{Materials and Methods}

The present investigation was carried out during rabi season 2011-12 at AICSIP, UAS, Dharwad. The plant material for this experiment comprised of 208 accessions of mini core collection obtained from DSR 
Hyderabad. The experiment was laid out in medium deep black soil under rain fed condition. The randomized block design was followed separately with two replications and each entry was sown in four rows of $4 \mathrm{~m}$ length with inter row spacing of $45 \mathrm{~cm}$ and intra row spacing of $15 \mathrm{~cm}$. Observations on all quantitative characters like plant height $(\mathrm{cm})$, panicle length $(\mathrm{cm})$, panicle width $(\mathrm{cm})$, seed yield per plot $(\mathrm{g}), 100$ seed weight $(\mathrm{g})$, seed volume $(\mathrm{ml})$, bulk density $(\mathrm{g} / \mathrm{ml})$, true density $(\mathrm{g} / \mathrm{ml})$ and seed size $(\mathrm{mm})$.

Seed size was measured by using Vernier Callipers where length, breadth and thickness of seeds were recorded. Seed density classified into two types viz., true density and bulk density. Seed bulk density was measured by hundred gram of seeds were weighed and volume was recorded in a measuring jars. Whereas, seed true density was observed by known weight of seeds placed in a measuring jar containing known quantity of toluene. Increase in volume was recorded after pouring seeds in measuring jar. Seed volume was noted with countable numbers of seeds were placed in a measuring jar. Grain quality characters like seed luster, seed color, seed shape and seed hardness was recorded by measuring the grinding time required to obtain a fixed volume of flour from the grains. Mean of five plants for each entry was worked out and used for statistical analysis. Genetic diversity was studied using Mahalanobis $\mathrm{D}^{2}$ statistic and clustering was done following Tocher's method described by Rao (1952) for determining group constellation. Average inter and intra cluster distances were estimated as per the procedure outlined by Singh and Choudhary (1977).

The analysis of variance for the individual character and analysis of covariance for character pairs were carried out as described by Cochran and Cox (1957). Divergence was estimated by the multivariate analysis using
Mahalanobis's (1936) and $\mathrm{D}^{2}$ statistic as described by Rao (1952). On the basis of $\mathrm{D}^{2}$ values obtained, the variables were grouped into different clusters by employing Tocher's method (Rao, 1952). The percent contribution of each character to the total divergence was calculated by ranking each character on the basis of transformed uncorrelated values. Finally, the percent contribution for each character was calculated by taking total number of ranks of all the characters to hundred. The data were analyzed statistically using the software WINDOSTAT, developed by INDOSTAT services Ltd. Hyderabad, India.

\section{Results and Discussion}

The analysis of variance showed highly significant differences among the accessions for all the characters studied indicating the presence of considerable variability in the experimental material. Nature and magnitude of genetic diversity exists in the crop species will be utilized for formulating breeding programme. Mahalanobis' $D^{2}$ statistics is used to quantify the degree of divergence. It is based on second degree statistics and pattern obtained by $\mathrm{D}^{2}$ does not change with number of characters. Based on $\mathrm{D}^{2}$ statistics and tocher method 208 accessions were grouped into 15 clusters with variable number of entries revealing the presence of considerable amount of genetic diversity in the material. Among them, cluster III had largest with 21 accessions whereas cluster XIII had minimum with 5 accessions reflecting narrow genetic diversity among them. Cluster VIII with 19 accessions, Whereas, three cluster namely IV, V and XIV had 17 accessions followed by Cluster VI and $\mathrm{X}$ with 16 accessions, cluster $\mathrm{I}$ and $\mathrm{XV}$ with 15 accessions, cluster II and IX had 12 accessions each. Whereas, cluster VII had 11 accessions, cluster XI had 8 accessions and cluster XII had 7 accessions, respectively (Table-1). The narrow genetic diversity may 
be attributed to similarity in the base material from which they have been evolved.

Among nine quantitative traits studied, the highest contribution towards the divergence was by plant height (46.2\%).Similar results were reported by Kukadia et al., (1981), Sisodia et al., (1983), Dabholkar et al., (1983) and Mehendiratta and Sindhy (1972). Interestingly grain quality traits like seed size contributed $23.49 \%$ followed by bulk density $(12.03 \%)$, seed volume $(6.65 \%)$, true density $(5.44 \%)$ including seed yield per plant $(5.77 \%)$, which indicates that grain quality traits also contributing for diversity. However, the characters like ear head width $(0.39 \%)$, ear head length $(0.02 \%)$ and 100 seed weight $(0.01 \%)$ indicated narrow range of diversity among the mini core under study (Table-2).

The average intra (diagonal) and inter cluster (off diagonal) $\mathrm{D}^{2}$ values are presented in the table-5. The inter cluster distance $\mathrm{D}^{2}$ value ranged widely with minimum values of $\left(\mathrm{D}^{2}=197.61\right)$ and maximum value $\left(\mathrm{D}^{2}=5541.42\right)$ indicating high diversity among mini core and it was desirable to select mini core from clusters showing high inter cluster distance. Diversity among cluster varied from $\left(D^{2}=255.25\right)$ to $\left(D^{2}=4906.5\right)$ inter cluster distance (Table-3). Higher intra cluster distance indicates that genotypes in the respective clusters and the higher inter cluster distances have wider genetic distances between the genotypes which could be used in hybridization programme.

In the present investigation, the inter cluster distance was higher than intra cluster distance which indicated substantial diversity among the mini core accessions and there may be a greater opportunity for obtaining the rare but superior segregants from crosses between more divergent accessions. Similar results were also obtained by earlier investigators (Swami et al., 2015; Jain and Patel, 2013; and Mohanraj et al., 2006).
The maximum inter cluster distance observed was between cluster XI and XIII (5541.42) followed by cluster XI and XII (4942.89), cluster IX and XIII (4225.12) and cluster VII and XI (4225.12). Intra cluster distance $D^{2}$ ranged from 0 to 596.24 which was followed by cluster $\mathrm{V}\left(\mathrm{D}^{2}=570.19\right)$. The most of intra cluster distance was zero. The intra cluster distance $\mathrm{D}^{2}$ value ranged widely with minimum value of 0 were observed between most of the clusters followed by (230.13) cluster I and I and cluster I and II was (247.31).

Cluster mean analysis was calculated using Tocher's method for nine yield and its attributing traits and presented in Table 4. Higher cluster mean for plant height was observed in cluster XI (292.68) followed by cluster VIII (263.67) and cluster IX (263.34). Whereas, lower cluster mean was recorded in cluster XIII (98.17). For ear head length cluster mean was recorded in cluster IX (35) followed by cluster XI (32.92) and cluster X (31.27). However, lower cluster mean in cluster VII (19.33). For earhead width the highest cluster mean was recorded in cluster $\mathrm{X}$ (13.33) and lowest were recorded in cluster I, cluster VII and cluster XII (7.5). Highest and lowest cluster mean for seed yield per plant was recorded in cluster XIV (42.5) and cluster VIII (5.95), respectively.

Based on overall score across nine traits, the cluster were ranked. Accordingly, cluster XIII with overall scores of 38 across XV clusters secured first rank followed by cluster XII, cluster VII, cluster I and cluster IV are the top clusters, indicating the presence of most promising accessions in them and can be extensively used for further breeding programme to generate new material.

The purpose of principal component analysis is to reduce the volume of data. Watson and Eyzaguirre (2002) also reported that PCA of morphological characterization results could 
identify a few key or minimum descriptors that effectively account for the majority of the diversity observed, saving time and effort for future characterization efforts. Principal components approach is very helpful in deciding which agronomic traits of crop contributing most to yield, subsequently, these agronomic traits should be emphasized in the breeding program (Jain et al., 2016).

Figure.1 The mini core accession by trait biplots of rabi sorghum

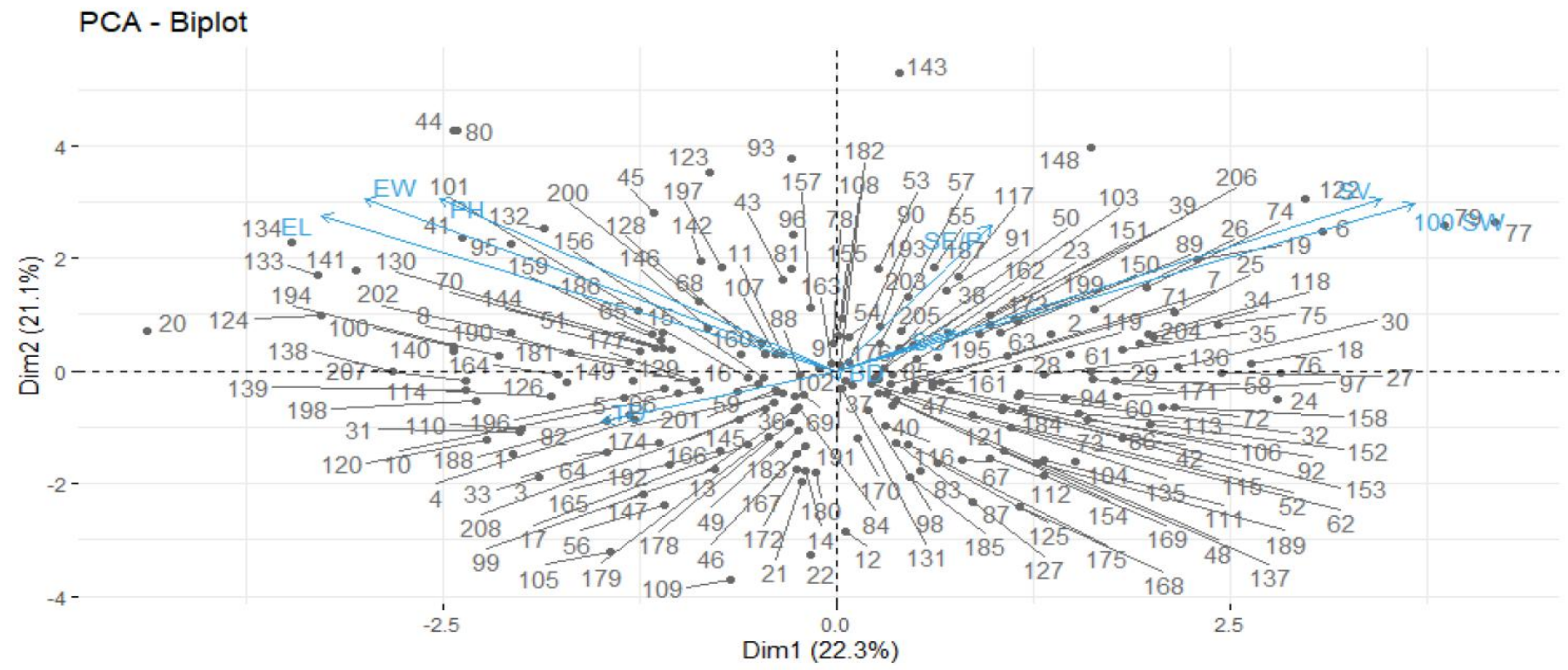

Table.1 Per cent contribution of characters towards divergence 208 mini core collections of rabi sorghum

\begin{tabular}{|r|l|r|}
\hline SI & Source & Contribution \% \\
\hline $\mathbf{1}$ & Plant height & $46.2 \%$ \\
\hline $\mathbf{2}$ & Ear head length & $0.02 \%$ \\
\hline $\mathbf{3}$ & Ear head width & $0.39 \%$ \\
\hline $\mathbf{4}$ & Seed yield per plant & $5.77 \%$ \\
\hline $\mathbf{5}$ & 100 seed weight & $0.01 \%$ \\
\hline $\mathbf{6}$ & Seed volume & $6.65 \%$ \\
\hline $\mathbf{7}$ & Bulk density & $12.03 \%$ \\
\hline $\mathbf{8}$ & True density & $5.44 \%$ \\
\hline $\mathbf{9}$ & Seed size & $23.49 \%$ \\
\hline
\end{tabular}


Table.2 Distribution of 208 mini core collections of rabi sorghum into different cluster

\begin{tabular}{|c|c|c|c|}
\hline $\begin{array}{l}\text { Cluster } \\
\text { No }\end{array}$ & $\begin{array}{l}\text { No. of } \\
\text { mini core }\end{array}$ & $\begin{array}{l}\text { Within } \\
\text { SS }\end{array}$ & Cluster members \\
\hline 1 & 15 & 0.6330 & $\begin{array}{l}\text { IS-602, IS-1233, IS-2389, IS-2413, IS-2426, IS-3971, IS-4060, IS-4951, IS-8012, IS-9177, IS-24453, IS- } \\
\text { 26749, IS-29714, IS-30572, IS-33353 }\end{array}$ \\
\hline 2 & 12 & 0.7812 & $\begin{array}{l}\text { IS-473, IS-1004, IS-4515, IS-6351, IS-10302, IS-10757, IS-12302, IS-13893, IS-14779, IS-25089, IS-27034, } \\
\text { IS-28449 }\end{array}$ \\
\hline 3 & 21 & 1.2792 & $\begin{array}{l}\text { IS-1041, IS-2864, IS-4360, IS-4698, IS-6354, IS-8916, IS-9108, IS-12735, IS-12883, IS-14010, IS-15466, } \\
\text { IS-15744, IS- 24953, IS-29241, IS-15466, IS-15744, IS-24953, IS-29241, IS-29269, IS-29565, IS-29568, IS- } \\
\text { 29606, IS-29654, IS-30383, IS-30443 }\end{array}$ \\
\hline 4 & 17 & 1.5104 & $\begin{array}{l}\text { IS-2382, IS-7131, IS-305, IS-11919, IS-13782, IS-16382, IS-19153, IS-19445, IS-28849, IS-29239, IS- } \\
\text { 29468, IS-29914, IS-30079, IS-30417 }\end{array}$ \\
\hline 5 & 17 & 2.1486 & $\begin{array}{l}\text { IS-995, IS-10867, IS-13294, IS-13549, IS-25910, IS-25989, IS-26222, IS-27887, IS-29233, IS-29392, IS- } \\
\text { 29304, IS-29733, IS-30092, IS-30400, IS-30838, IS-31043, IS-31557, IS-33023 }\end{array}$ \\
\hline 6 & 16 & 0.4695 & $\begin{array}{l}\text { IS-1219, IS-4631, IS-5094, IS- 5301, IS-6421, IS-13971, IS-14290, IS-15478, IS-18038, IS-25732, IS- } \\
\text { 26737, IS-29187, IS-29627, IS-30451, IS-30507, IS-31651 }\end{array}$ \\
\hline 7 & 11 & 0.6991 & $\begin{array}{l}\text { IS-4092, IS-12447, IS-14090, IS-19676, IS-24348, IS-24462, IS-27912, IS-28141, IS-29358, IS-29392, IS- } \\
29582\end{array}$ \\
\hline 8 & 19 & 3.4635 & $\begin{array}{l}\text { IS-20298,IS-20679, IS-20697, IS-20727, IS-21512, IS-21645, IS-21863, IS-22239, IS-22609, IS-22720, IS- } \\
\text { 22986, IS-23514, IS-23521, IS-23579, IS-23583, IS-23590, IS-23684, IS-23891 }\end{array}$ \\
\hline 9 & 12 & 5.4003 & IS-20625, IS-20632, IS-20740, IS-20743, IS-21083, IS-22294, IS-22626, IS-23216, IS-23992, IS-24139 \\
\hline 10 & 16 & 0.8129 & $\begin{array}{l}\text { IS-603,IS-608, IS-995, IS-1212, IS-5295, IS-5919, IS-12945, IS-19389, IS-24939, IS-25548, IS-26694, IS- } \\
\text { 29314, IS-30460, IS-30536, IS-31186 }\end{array}$ \\
\hline 11 & 8 & 0.7865 & IS-7987, IS-15931, IS-15945, IS-19975, IS-26025, IS-26484, IS-28451, IS-28614 \\
\hline 12 & 7 & 1.4604 & IS-7250, IS-7310, IS-7679, IS-25242, IS-25301, IS-26046, IS-28747 \\
\hline 13 & 5 & 0.8236 & IS-2397, IS-2872, IS-3158, IS-19262, IS-29950 \\
\hline 14 & 17 & 0.6332 & $\begin{array}{l}\text { IS-2379, IS-4581, IS-4613, IS-6421, IS-9113, IS-12937, IS-16151, IS-17980, IS-24463, IS-24492, IS-26701, } \\
\text { IS-29326, IS-29335, IS-29689, IS-29772, IS-30450 }\end{array}$ \\
\hline 15 & 15 & 0.9438 & $\begin{array}{l}\text { IS-2902, IS-8774, IS-12706, IS-13919, IS-14861, IS-15170, IS-19450, IS-19859, IS-25836, IS-28313, IS- } \\
\text { 29441, IS-29519, IS-30538, IS-31714 }\end{array}$ \\
\hline
\end{tabular}


Table.3 Average $\mathrm{D}^{2}$ values of intra and inter cluster distances among 208 mini core collections of rabi sorghum

\begin{tabular}{|c|c|c|c|c|c|c|c|c|c|c|c|c|c|c|c|}
\hline Cluster & $\begin{array}{l}\text { Cluster } \\
\text { I }\end{array}$ & $\begin{array}{l}\text { Cluster } \\
\text { II }\end{array}$ & $\begin{array}{l}\text { Cluster } \\
\text { III }\end{array}$ & $\begin{array}{l}\text { Cluster } \\
\text { IV }\end{array}$ & $\begin{array}{l}\text { Cluster } \\
\text { V }\end{array}$ & $\begin{array}{l}\text { Cluster } \\
\text { VI }\end{array}$ & $\begin{array}{l}\text { Cluster } \\
\text { VII }\end{array}$ & $\begin{array}{l}\text { Cluster } \\
\text { VIII }\end{array}$ & $\begin{array}{l}\text { Cluster } \\
\text { IX }\end{array}$ & $\begin{array}{l}\text { Cluster } \\
\text { X }\end{array}$ & $\begin{array}{l}\text { Cluster } \\
\text { XI }\end{array}$ & $\begin{array}{l}\text { Cluster } \\
\text { XII }\end{array}$ & $\begin{array}{l}\text { Cluster } \\
\text { XIII }\end{array}$ & $\begin{array}{l}\text { Cluster } \\
\text { XIV }\end{array}$ & $\begin{array}{l}\text { Cluster } \\
\text { XV }\end{array}$ \\
\hline $\begin{array}{l}\text { Cluster } \\
\text { I }\end{array}$ & 230.13 & 583.66 & 516.19 & 1053.52 & 459.46 & 455.31 & 949.28 & 1225.29 & 1126.62 & 1561.84 & 1693.2 & 1221.3 & 1468.32 & 1381.21 & 829.85 \\
\hline $\begin{array}{l}\text { Cluster } \\
\text { II }\end{array}$ & & 247.31 & 1449.25 & 1362.04 & 785.64 & 1026.81 & 449.02 & 2191.09 & 2428.62 & 2811.28 & 3330.21 & 373.93 & 575.67 & 1799.39 & 1299.95 \\
\hline $\begin{array}{l}\text { Cluster } \\
\text { III }\end{array}$ & & & 323.5 & 1417.27 & 760.53 & 599.27 & 2008.31 & 1034.7 & 545.11 & 1121.36 & 886.14 & 2504.93 & 2815.12 & 1690.87 & 947.62 \\
\hline $\begin{array}{l}\text { Cluster } \\
\text { IV }\end{array}$ & & & & 373.65 & 1442.88 & 1231.76 & 1731.23 & 602.41 & 1944.02 & 1067.37 & 2893.72 & 1768.22 & 1910.46 & 649.15 & 1922.73 \\
\hline $\begin{array}{l}\text { Cluster } \\
\text { V }\end{array}$ & & & & & 5770.19 & 839.51 & 1162.22 & 1690.12 & 1350.38 & 1930.15 & 1832.08 & 1522.88 & 1881.72 & 1509.75 & 1040.33 \\
\hline $\begin{array}{l}\text { Cluster } \\
\text { VI }\end{array}$ & & & & & & 260.9 & 1080.54 & 1072.24 & 1355.03 & 1615.05 & 1811.89 & 1812.28 & 1687.81 & 1526.97 & 1598.48 \\
\hline $\begin{array}{l}\text { Cluster } \\
\text { VII }\end{array}$ & & & & & & & 0 & 2602.62 & 3561.47 & 3575.37 & 4225.12 & 601.67 & 435.73 & 1783.18 & 2462.68 \\
\hline $\begin{array}{l}\text { Cluster } \\
\text { VIII }\end{array}$ & & & & & & & & 0 & 1142.4 & 509.4 & 1931.98 & 3113.22 & 3166.75 & 900.84 & 2131.91 \\
\hline $\begin{array}{l}\text { Cluster } \\
\text { IX }\end{array}$ & & & & & & & & & 0 & 1053.95 & 629.13 & 3725.28 & 4290.56 & 2460.67 & 1033.13 \\
\hline $\begin{array}{l}\text { Cluster } \\
\text { X }\end{array}$ & & & & & & & & & & 480.5 & 1521.27 & 3883.24 & 4247.78 & 1244.99 & 1945.98 \\
\hline $\begin{array}{l}\text { Cluster } \\
\text { XI }\end{array}$ & & & & & & & & & & & 596.24 & 4942.89 & 5541.42 & 2982.2 & 1650.1 \\
\hline $\begin{array}{l}\text { Cluster } \\
\text { XII }\end{array}$ & & & & & & & & & & & & 0 & 197.61 & 2567.58 & 1820.74 \\
\hline $\begin{array}{l}\text { Cluster } \\
\text { XIII }\end{array}$ & & & & & & & & & & & & & 0 & 2638.1 & 2710.63 \\
\hline $\begin{array}{l}\text { Cluster } \\
\text { XIV }\end{array}$ & & & & & & & & & & & & & & 0 & 2871.46 \\
\hline $\begin{array}{l}\text { Cluster } \\
\text { XV }\end{array}$ & & & & & & & & & & & & & & & 0 \\
\hline
\end{tabular}


Table.4 Clusters means of 9 quantitative characters among 208 mini core collections of rabi sorghum.

\begin{tabular}{|c|c|c|c|c|c|c|c|c|c|}
\hline $\begin{array}{c}\text { Cluster } \\
\text { No }\end{array}$ & $\begin{array}{c}\text { Plant } \\
\text { Height }\end{array}$ & $\begin{array}{c}\text { Ear head } \\
\text { length }\end{array}$ & $\begin{array}{c}\text { Ear head } \\
\text { width }\end{array}$ & $\begin{array}{c}\text { Seed yield } \\
\text { per plant }\end{array}$ & $\begin{array}{c}\text { 100 seed } \\
\text { weight }\end{array}$ & $\begin{array}{c}\text { Seed } \\
\text { volume }\end{array}$ & $\begin{array}{c}\text { Bulk } \\
\text { Density }\end{array}$ & $\begin{array}{c}\text { True } \\
\text { Density }\end{array}$ & $\begin{array}{c}\text { Seed } \\
\text { size }\end{array}$ \\
\hline I & 190.55 & 20.76 & 7.5 & 27.17 & 2.49 & 0.04 & 0.71 & 1.26 \\
\hline II & 136.74 & 21.7 & 6.88 & 25.44 & 2.5 & 0.04 & 0.73 & 1.29 \\
\hline III & 234.52 & 26.15 & 9.88 & 28.29 & 2.28 & 0.04 & 0.7 & 1.29 \\
\hline IV & 176.06 & 21.66 & 7.57 & 27.13 & 2.58 & 0.04 & 0.71 & 1.31 \\
\hline V & 191.82 & 21.59 & 7.99 & 30.75 & 3.06 & 0.05 & 0.74 & 1.3 \\
\hline VI & 202.19 & 25.1 & 10.05 & 27.25 & 2.04 & 0.03 & 0.56 & 1.2 \\
\hline VII & 122.17 & 19.33 & 7.5 & 15.15 & 3.56 & 0.06 & 0.59 & 1.1 \\
\hline VIII & 263.67 & 28.33 & 8.5 & 5.95 & 1.47 & 0.04 & 0.63 & 1.42 \\
\hline IX & 263.34 & 35 & 8.34 & 27.7 & 1.97 & 0.03 & 0.77 & 1.64 \\
\hline X & 249.87 & 31.27 & 13.33 & 33.36 & 2.62 & 0.04 & 0.75 & 1.29 \\
\hline XI & 292.68 & 32.92 & 11.19 & 29.93 & 2.66 & 0.04 & 0.74 \\
\hline XII & 97.17 & 20 & 4.84 & 25.75 & 2.39 & 0.03 & 0.79 & 1.28 \\
\hline XIII & 89.17 & 25.84 & 7.5 & 28.25 & 1.75 & 0.03 & 0.63 & 1.24 \\
\hline XIV & 188.33 & 21.5 & 10.5 & 42.5 & 4.23 & 0.09 & 0.67 & 1.24 \\
\hline XV & 202.83 & 27.5 & 8.84 & 13.05 & 1.78 & 0.01 & 0.95 & 1.24 \\
\hline
\end{tabular}


Table.5 Principal component analysis of measured traits in 208 mini core accessions of rabi sorghum

\begin{tabular}{|c|c|c|c|c|c|c|c|c|c|}
\hline & $\begin{array}{l}\text { Plant } \\
\text { height }\end{array}$ & $\begin{array}{l}\text { Earhead } \\
\text { length }\end{array}$ & $\begin{array}{l}\text { Earhead } \\
\text { width }\end{array}$ & $\begin{array}{l}\text { Seed yield } \\
\text { per plant }\end{array}$ & $\begin{array}{l}100 \text { seed } \\
\text { weight }\end{array}$ & $\begin{array}{l}\text { seed } \\
\text { volume }\end{array}$ & $\begin{array}{l}\text { Bulk } \\
\text { density }\end{array}$ & $\begin{array}{l}\text { True } \\
\text { density }\end{array}$ & Seed size \\
\hline eigenvalue & 2.01 & 1.9 & 1.34 & 1.05 & 0.9 & 0.63 & 0.55 & 0.43 & 0.2 \\
\hline variance.percent & 22.31 & 21.12 & 14.86 & 11.66 & 10 & 7.03 & 6.1 & 4.75 & 2.18 \\
\hline cumulative.variance.percent & 22.31 & 43.43 & 58.29 & 69.94 & 79.95 & 86.98 & 93.07 & 97.82 & 100 \\
\hline
\end{tabular}

Table.6 Factor loadings of the study traits of the first three principal components (PCs)

\begin{tabular}{|l|c|c|c|}
\hline \multicolumn{1}{|c|}{ Traits } & \multicolumn{3}{|c|}{ Mini core } \\
\cline { 2 - 4 } & PC1 & PC2 & PC3 \\
\hline PH & -0.3390 & 0.4228 & -0.0093 \\
\hline EL & -0.4392 & 0.3813 & -0.1143 \\
\hline EW & -0.4030 & 0.4218 & 0.1124 \\
\hline SE/P & 0.4949 & 0.4089 & -0.2060 \\
\hline 100 SW & 0.1322 & 0.3566 & 0.0709 \\
\hline SV & 0.4660 & 0.4217 & -0.0953 \\
\hline BD & 0.0022 & -0.0248 & -0.7121 \\
\hline TD & -0.1997 & -0.1234 & -0.6403 \\
\hline SS & 0.1015 & 0.0997 & 0.0252 \\
\hline
\end{tabular}


A screen plot is a simple line segment plot that shows the fraction of total variance in the data. It is a plot, in descending order of magnitude, of the eigen values of a correlation matrix. According to Chatfied and Collins (1980), components with an eigenvalue of $<1$ should be eliminated so that fewer components are dealt with. Sharma (1998) reported that PCA reflects the importance of the largest contributor to the total variation at each axis of differentiation. It was further reported by Fenty (2004) that PCA reduces a large set of variables to come up with smaller sets of components those summaries the correlations. The Screen plot of the PCA (Fig. 1) shows that the first three eigenvalues correspond to the whole percentage of the variance in the dataset.

Three out of nine principal components with eigenvalues $>1$ were extracted. These three components contributed $58.29 \%$ of the total variation among the germplasm. Principal components 1, 2, and 3 contributed, respectively, $22.73 \%, 17.99 \%$, and $15.50 \%$ toward the variation observed among genotypes (Table-5). The aim of principal component analysis is to resolve the total variation of a set of traits into linear, independent composite traits, which successively maximize variability in the data (Johnson 2012). Sample traits are generally inter-correlated to varying degrees and hence not all principal components are needed to summarize the data adequately. In this study, the first three principal components represented a sizeable amount of diversity among the genotypes investigated. This implied that several traits were involved in explaining the variation among the genotypes. Ayana and Bekele (1999) reported significance of first five PCs in the total variability of different agro-morphological traits in sorghum. The first four principal components, with eigenvalues greater than one, were also documented in 25 forage and
45 grain sorghum genotypes for dual purpose (Chikuta et al., 2015). Abraha et al., (2015) reported four principal components with eigenvalues greater than one, which explained $>75 \%$ of the total variation for grain yield, biomass, stay-green, leaf area, peduncle exertion, days to flowering, and maturity. Around 44\%, 17\%, and $15 \%$ variation attributed to first, second, and third principal components, respectively, was reported by Chikuta et al., (2015). Several studies on principal component analysis of different agro-morphological traits in sorghum have been documented. Abraha et al., (2015) concluded that grain yield, biomass, staygreen, leaf area, peduncle exertion, days to flowering, and maturity were the most important traits for genetic variability in landrace sorghums. On the other hand, head width, head weight, grain yield per plant, and fresh and dry shoot weight were found to be the most important traits for drought tolerance in grain sorghum (Ali et al., 2011).

The phenotypic diversity observed in this study was attributable to several traits (Table6). Variation relative to the first component was associated with seed yield per plant, 100 seed weight, seed volume, bulk density, seed size. The second principal component was associated with plant height, ear head length, ear head width, seed yield per plant, 100 seed weight, seed volume and seed size. The third principle component was associated with ear head width, 100 seed weight, seed yield per plant and seed size. Distribution of biometrical traits in first two components is sown in loading plot (Fig. 1). The loading plot clearly showed that plant height, panicle length, panicle width, seed yield per plot, 100 seed weight, seed volume, bulk density, true density and seed size contributed traits towards diversity. In this study, concluded that significant diversity existed among mini core accessions of sorghum for the traits studied. Efficient exploitation of this diversity 
is helpful in identifying sorghum parental lines for hybrid breeding program. Intercrossing between accessions from diverse clusters will provide segregating sorghum progeny for yield; thereby, leading to the development of high-yielding varieties.

\section{Acknowledgement}

The senior author is greatful to DSR Hyderabad for providing mini core collection.

\section{References}

Anonymous. World Agricultural production, 2019a, 21.

Anonymous. World Agricultural production, 2019b, 21

Abraha, T., Githiri, S. M. Kasili, R. Araia, W. and Nyende. A. B. (2015). "Genetic variation among sorghum (Sorghum bicolor (L.) Moench) landraces from eritrea under postflowering drought stress conditions." American Journal of Plant Sciences. 6 (09): 1410. doi:10.4236/ajps.2015.69141

Ali, M. A., Jabran, K., Awan, S. I., Abbas, A., Zulkiffal, M., Acet, T. and Rehman, A. (2011). "Morpho-physiological diversity and its implications for improving drought tolerance in grain sorghum at different growth stages." Australian Journal of Crop Science. 5 (3): 311 .

Ayana, A. and Bekele, E. (1999). "Multivariate analysis of morphological variation in sorghum (Sorghum bicolor (L.) Moench) germplasm from ethiopia and eritrea." genetic resources and crop evolution. $46 \quad$ (3): 273-84. doi:10.1023/A:1008657120946.

Bello, D. (2004). "Genetic variability and inter-relationship of traits in local sorghum (Sorghum bicolor (L.) Moench) in adamawa state." unpublished M.Sc. Thesis, Yola:
Federal University of Technology.

Chikuta, S., Odong, T., Kabi, F. and Rubaihayo, P. (2015). "Phenotypic diversity of selected dual purpose forage and grain sorghum genotypes." American Journal of Experimental Agriculture $\quad 9: \quad 6$. doi:10.9734/AJEA/2015/20577.

Cochran, W.C. and Cox, G.M. (1957). Experimental designs. John Wiley and Sons, N.Y. London, pp. 82-90.

Das, L. V. (2000). Problems facing plant breeding. New Delhi: CBS.

Jain, S.K. and Patel, P.R. (2013). Multivariate analyses in sorghum [Sorghum bicolor (L.) Moench] for fodder yield and their attributes. Agric. Sci. Digest. 33(3):215218.

Johnson, D. E. (2012). Applied multivariate methods for data analysis. New York: Duxbury Press.

Kotal, B. D., Das, A. and Choudry, B. K. (2010). Genetic variability and association of characters in wheat (Triticum aestivumL.). Asian J. Crop Sci. 2:155-160.

Mahalanobis, P.C. (1936). On the generalized distance in statistics. Proceedings of National Institute of Sciences, India. 2:49-55

Mary, S. S. and Gopalan, A. (2006). "Dissection of genetic attributes yield traits of fodder cowpea in $\mathrm{F}_{3}$ and $\mathrm{F}_{4}$." Journal Applications Sciences Researcher.2 (6): 805-08.

Mohanraj, K., Gopalan, A. and Shanmuganathan, M. (2006). Genetic diversity in sorghum [Sorghum bicolor (L.) Moench].The Journal of Agricultural Sciences, 2 (2):06-11.

Murty, B.R. and Arunachalam, V.(1966). The nature and divergence in relation to breeding systems in some crop plants. Indian Journal of Genetics. 22:66-80

Rao, C.R. (1952). Advanced statistical methods in biometrical research. New 
York, USA. John Wiley and Sons Inc. Sanchez, A., Subudhi, P. Rosenow, D. and H. Nguyen, 2002. Mapping QTLs associated with drought resistance in sorghum (Sorghum SW (L.) Moench). Plant molecular biology, 48(5-6): 713726

Sonawane, M.N., and Patil. F.B. (1991). Genetic divergence in cowpea. Journal of Maharashtra Agricultural University. 6: 167-169.

Swami, S.S., Chaudhary, S.B. and Kute, N.S. (2015). Genetic diversity studies in rabi sorghum [Sorghum bicolor (L.) Moench]. Journal of Agricultural
Research Technology. 40(2): 203-207.

Watson, J.W. and Eyzaguirre, P.P.B. (2002). Homegardens and in situ conservation of plant genetic resources in farming systems. Proceedings of the second international home gardens workshop, 17-19th July 2001, Witzenhausen, Federal Republic of Germany. International Plant Genetic Resources Institute, Rome, Italy.

Yan, W. and Kang. M. S. (2003). GGE Biplot Analysis: A graphical tool for breeders, Geneticists, and Agronomists. Boca Raton, FL: CRC Press.

\section{How to cite this article:}

Ashwini Karadi and Kajjidoni, S.T. 2019. Genetic Diversity and Principal Component Analysis for Grain Quality and Productivity Traits in Sorghum [Sorghum bicolor (L.) Moench]. Int.J.Curr.Microbiol.App.Sci. 8(09): 839-850. doi: https://doi.org/10.20546/ijcmas.2019.809.101 